\title{
HF Doppler radar observations of sporadic $E$ at an Indian low latitude station, Visakhapatnam
}

\author{
M. S. S. R. K. N. Sarma, C. Raghava Reddy, and K. Niranjan \\ Department of Physics, Andhra University, Visakhapatnam 530 003, India \\ Received: 6 June 2008 - Revised: 24 November 2008 - Accepted: 7 January 2009 - Published: 2 February 2009
}

\begin{abstract}
MHz HF Doppler radar observations of Sporadic $\mathrm{E}$ over an Indian low latitude station, Visakhapatnam $\left(17.7^{\circ} \mathrm{N}, 83.3^{\circ} \mathrm{E}\right.$ and Dip $\left.20^{\circ}\right)$ with $10 \mathrm{~s}$ resolution showed quasi-periodic variations of the echo strength and Doppler velocity variations with periods of a few minutes to a few tens of minutes. The echo strength and Doppler velocity variations with time in different range bins of the $E_{S}$ echo showed variations which are some times similar and some times significantly different in successive range bins at intervals of $7.5 \mathrm{~km}$. The $E_{S}$ echo occurs with the height of maximum echo strength in the range of $100 \mathrm{~km}$ to $120 \mathrm{~km}$ and some times at $130 \mathrm{~km}$. The altitude variation of the average Doppler velocity is highly variable and the height of maximum echo strength is not the same as the height of maximum Doppler velocity. Observations of $E_{S}$ echoes at different times of the day are presented to bring out the differences between the day and night time $E_{S}$ echoes. The relationship between Radar and $E_{S}$ parameters derived from Ionograms is poorer than that of mid latitudes which is quite consistent with the expectations based on gradient drift instability.
\end{abstract}

Keywords. Ionosphere (Equatorial ionosphere; Ionization mechanisms; Ionospheric irregularities)

\section{Introduction}

Sporadic-E or $E_{S}$ has been a topic of active research for more than four decades and the occurrence characteristics of $E_{S}$ in different latitude and longitude regions obtained from analysis of the huge wealth of HF sounders data was well documented. The formation of $E_{S}$ layers at $\mathrm{E}$ region heights was explained by the wind shear theory (Dungey, 1956, 1959;

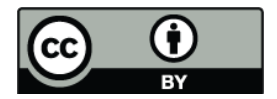

Correspondence to: K. Niranjan (niranjankandula@hotmail.com)
Axford, 1961; Whitehead, 1961). Field-aligned irregularities (FAI) in the equatorial and auroral $\mathrm{E}$ region have been reported by Fejer and Kelley (1980); and Haldoupis (1989). With the advent of high power VHF radars, there have been some reports on E region FAI in the mid-latitudes (Keys and Andrews, 1984; Ecklund et al., 1981; Riggin et al., 1986; Yamamoto et al., 1991) and these were reported to be closely associated with $E_{S}$ layers. Tanaka and Venkateswaran (1982a, b) analyzing $25 \mathrm{MHz}$ radar data, reported similar observations from Iioka, Japan $\left(35.7^{\circ} \mathrm{N}, 140.8^{\circ} \mathrm{E}\right)$. These meter scale irregularities producing coherent (Bragg's) scatter for radar beam incidence orthogonal to the geomagnetic field, appear to be generated by gradient drift instability mechanism (Simon, 1963; Kato, 1972).

Yamamoto et al. (1991) using MU radar observations in five antenna beam directions, all orthogonal to the geomagnetic field at $100 \mathrm{~km}$ altitude, reported that two types of FAI echoes, one appearing continuously after sunrise, and another after sunset with quasi-periodic variations. The continuous echoes are from 90 to $100 \mathrm{~km}$ altitude and the quasi-periodic $(\mathrm{QP})$ echoes were intermittent with periods 5 to $10 \mathrm{~min}$ and were from altitudes above $100 \mathrm{~km}$. The QP echoes were reported from many radars locations (Yamamoto et al., 1991, 1992, 1994; Woodman et al., 1991; Tsunoda et al., 1994, 1995), which were reported to be usually located in the valley region between the E- and F-regions and extend from $177 \mathrm{~km}$ to $215 \mathrm{~km}$ (Tsunoda et al., 1995) and the slope of the range rate was about $-100 \mathrm{~m} / \mathrm{s}$ and always negative. The QP echoes first reported by Balsley (1964) as $150 \mathrm{~km}$ echoes were studied close to the magnetic equator in great detail (Royrvik and Miller, 1981; Royrvik, 1982; Kudeki and Fawcett, 1993; Hysell et al., 1997; Chau and Woodman, 2004; Chau, 2004; Kudeki et al., 1998; Tsunoda and Euklund, 2000, 2004; Blank et al., 1996; de Paula and Hysell, 2004). There were reports from the Indian MST radar at Gadanki outside the equatorial electrojet (Geomag. Lat. $6.3^{\circ} \mathrm{N}$ ) in India (Choudhary et al., 2004; Patra and

Published by Copernicus Publications on behalf of the European Geosciences Union. 


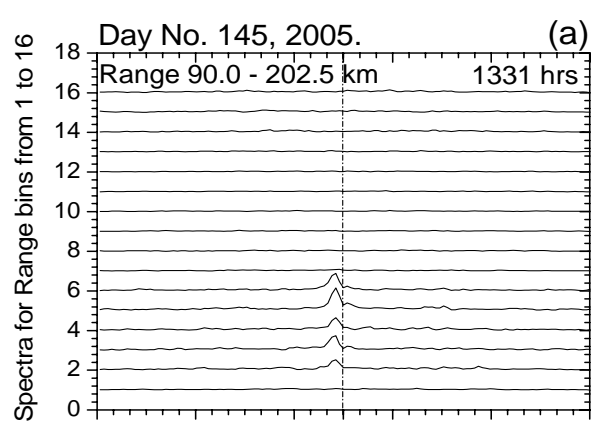

(b)
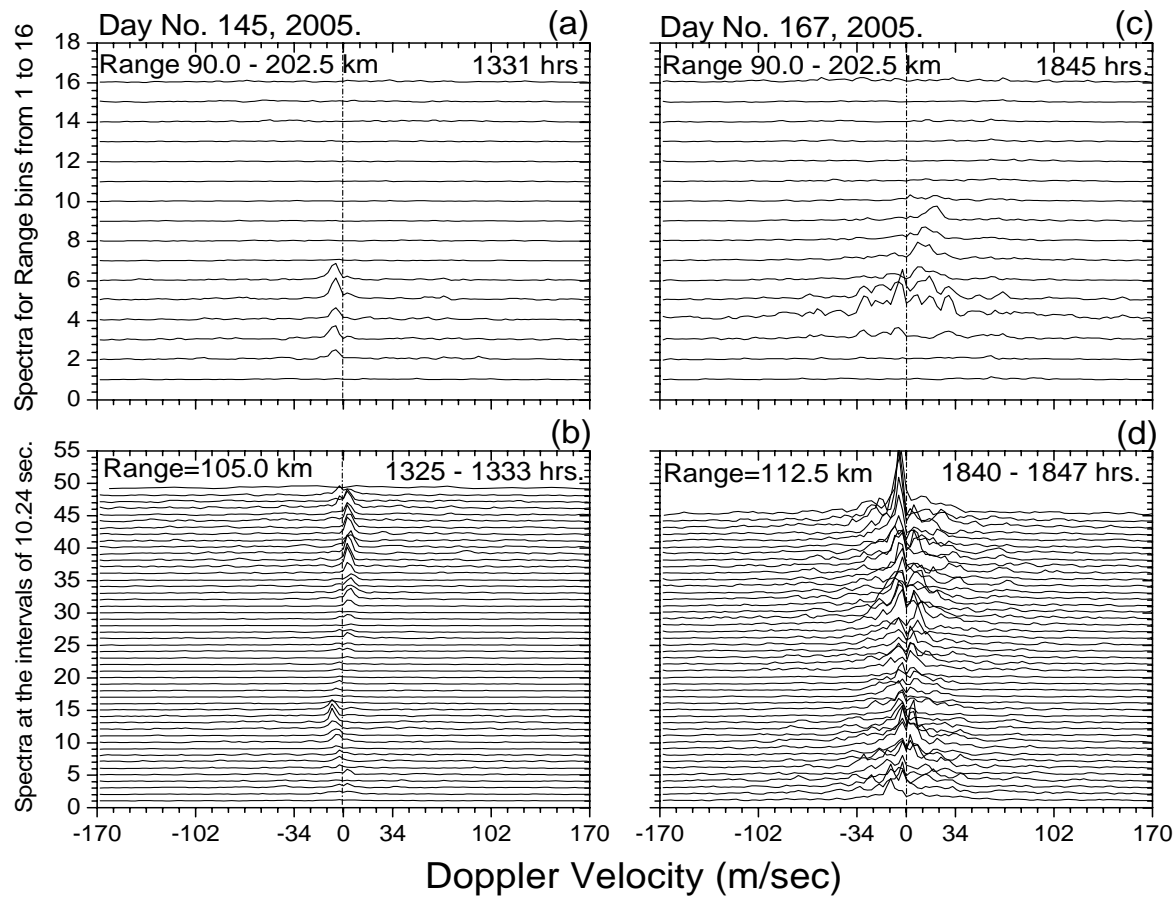

(c)

(d)

Fig. 1. (a) Spectra of the signals received in the 16 range bins for day no. 145, 2005 (25 May 2005), (b) Doppler spectra of $E_{S}$ echo in range bin 3 (range $105 \mathrm{~km}$ ) at successive intervals of $10.24 \mathrm{~s}$, (c) is similar to (a) except for day no. 167, 2005 (14 June 2005)and (d) is similar to (b) except for day no. 167, 2005 and range bin 4 (range $112.5 \mathrm{~km}$ ). Positive velocities indicate upward motion and negative velocities indicate downward motion.

Venkateswara Rao, 2006) on the daytime $150 \mathrm{~km}$ echoes having characteristics similar to those reported from near the magnetic equator.

Almost all HF radars built and operated in different geographical locations did not have the Doppler spectrum capability and hence the characteristics of $E_{S}$ from them were limited to occurrence characteristics and relationship with geophysical phenomena. In this study the characteristics of $E_{S}$ echoes observed over a low latitude Indian station Visakhapatnam $\left(17.7^{\circ} \mathrm{N}, 83.3^{\circ} \mathrm{E}\right)$, at different local times using $5.5 \mathrm{MHz}$ Doppler radar with spectral capability are presented. The characteristics of $E_{S}$ echoes at different altitudes are studied for each occurrence of $E_{S}$ using the plots of Range Time SNR (RTS), phase height variation with time at the range where the echo intensity is high and Doppler velocity at all range bins. This study is essentially concerned with the detailed structure of $E_{S}$ echo signal strength and Doppler velocity at different altitudes at different times of the day as observed by HFD radar.

\section{Observational description}

At the low latitude station Visakhapatnam the critical frequency of normal E-region never exceeds $4 \mathrm{MHz}$ and any $5.5 \mathrm{MHz}$ radar echoes from $95 \mathrm{~km}$ to $140 \mathrm{~km}$ altitudes were taken to be from $E_{S}$ layer. Nearly forty events of $E_{S}$ were recorded during the year 2005. The occurrences were more frequent during the day time than at the night. We present five typical cases of AUHFD radar observations of $E_{S}$ at different times of the day and in all the cases the $15 \mathrm{~min}$ ionograms recorded at Visakhapatnam showed $E_{S}$.

The data recorded in successive files were arranged sequentially to form a continuous time series of I \& $\mathrm{Q}$ values for each range bin and were analyzed by 512 point FFT routine to compute the complex Doppler spectra at intervals of 10.24 s. For each Doppler spectrum, the signal to noise ratio $(\mathrm{S} / \mathrm{N})$, line of sight velocity $(\mathrm{V})$ and the spectral width (SW) were computed from the three lower, 0th, 1st and 2nd, order moments (denoted as $\mathrm{M}_{0}, \mathrm{M}_{1}$ and $\mathrm{M}_{2}$ respectively) representing the echo power $\left(P_{S}\right)$, weighted mean Doppler shift $\left(\overline{f_{d}}\right)$ and variance $\left(f_{w}^{2}\right)$ which is a measure of the dispersion from the mean Doppler frequency $\left(\overline{f_{d}}\right)$, respectively, using the expressions given by Woodman (1985).

The echoes in different range bins, in principle, could be from echoing regions displaced horizontally or vertically or both. For horizontally displaced echoing regions, the echoes in each range bin would be from a constant zenith angle but from various azimuth directions and for larger range the zenith angle would be larger. In such a case the spectra for each range bin would be symmetrical with both positive and negative Doppler velocities that were never observed and therefore it can be concluded that the echoes of larger range are essentially from higher heights. 

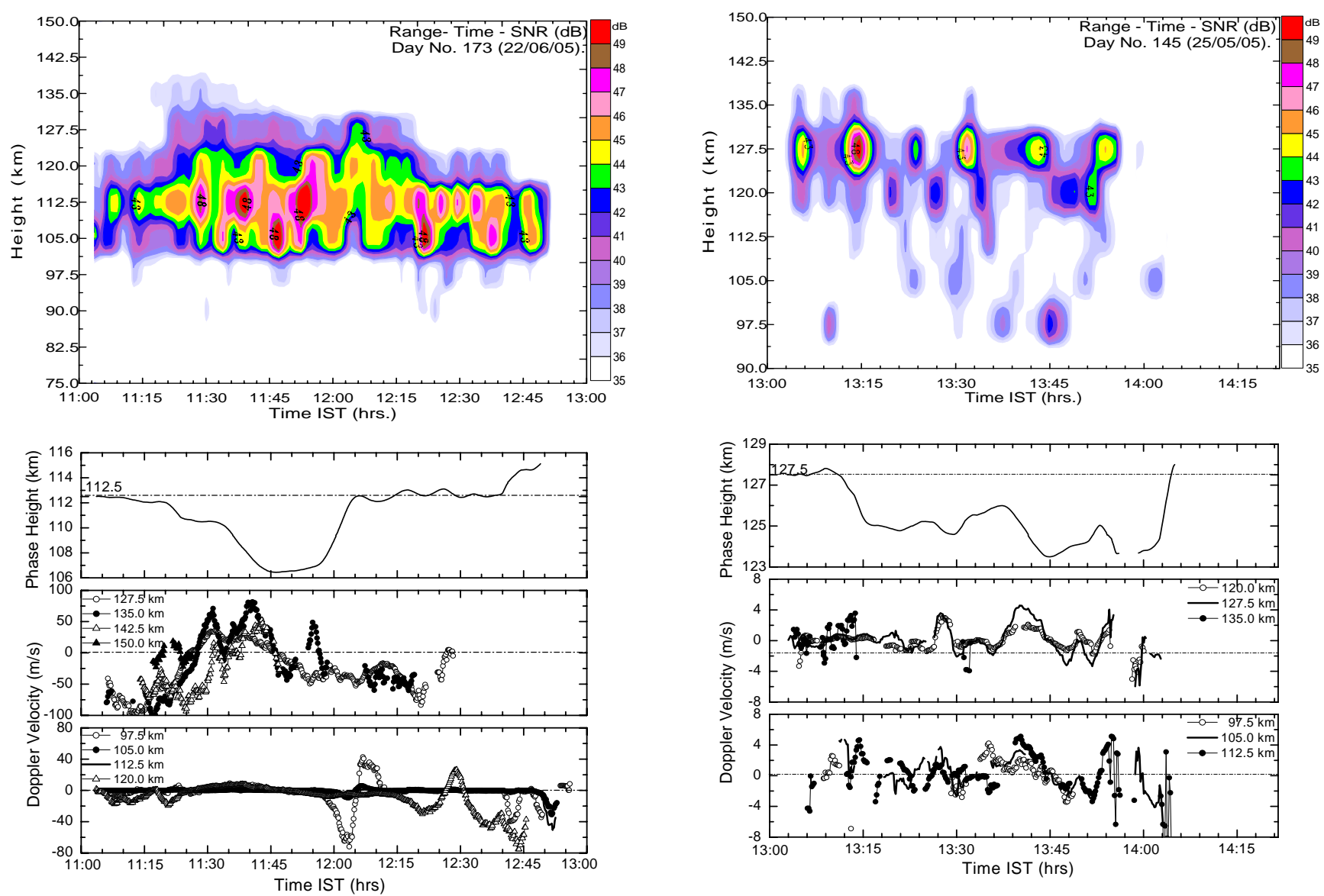

Fig. 2. Top panel shows Range Time Intensity maps for Day no. 173 (22 June 2005). Second panel shows phase height variation of the echo at the range bin where echo intensity is highest. And bottom two panels show the time variations of line of sight Doppler velocity in each range bin.

\section{Doppler spectra of $E_{S}$ echoes}

Figure 1a shows the spectra of Radar echoes in all the 16 range bins. $E_{S}$ echo peaks are seen in range bins 1 to 6 (heights $97.5 \mathrm{~km}$ to $135 \mathrm{~km}$ in steps of $7.5 \mathrm{~km}$ ) with $-5.326 \mathrm{~m} / \mathrm{s}$ Doppler velocity. Normally, the Doppler velocity in sets of three successive range bins is the same because of the $100 \mu$ s transmitter pulse width while the range bins are at $50 \mu$ s intervals and that the echoes are from two discrete reflecting layers producing the same Doppler velocities. Figure $1 \mathrm{~b}$ shows time series of successive spectra for range bin $3(105 \mathrm{~km})$ at intervals of $10.24 \mathrm{~s}$ from 13:25 to 13:33 IST. The echo intensity (I) and Doppler velocity can be seen to vary with time. Figure 1c shows two discrete reflecting layers with different velocities. In the lower range bins (i.e. from $105 \mathrm{~km}$ to $127.5 \mathrm{~km}$ ) the echoes are diffused whereas specular echoes were observed in the higher range bins. The weighted mean Doppler velocities differ by less than a meter/s in successive range bins. Figure 1d shows time

Fig. 3. Same as Fig. 2 except for the Day no. 145, 2005 (25 May 2005).

variations of the spectra of the same event shown in Fig. 1c, in range bin $4(112.5 \mathrm{~km})$. The multiple peaks in each spectrum indicate the presence of echoes not resolved in range, unlike in the event shown in Fig. $1 b$.

\section{The Range-Time-S/N (RTS) variations during $E_{S}$ at different times of the day}

Figures 2, 3, 4, 5 and 6 show the temporal variations of SNR (top panel of each figure), phase height (middle panel) and Doppler velocity (bottom two panels for different heights) of $E_{S}$ during the different times of the day, viz., forenoon, afternoon, pre sunset, post sunset and post mid night hours. The Range Time Signal to noise ratio (RTS) variation shown in top panels is equivalent to Range Time Intensity (RTI) maps since the noise power per frequency bin is fairly constant for all ranges of $E_{S}$ echoes. The signal intensity "I" for each range bin is sum of the squares of the signal amplitudes of all Doppler frequency bins from $-6.5 \mathrm{~Hz}$ to $+6.5 \mathrm{~Hz}$ and $\mathrm{S} / \mathrm{N}$ was calculated for the same Doppler bins. The echoes started appearing about five minutes earlier than the starting times shown in the plots, which is time taken for setting the 

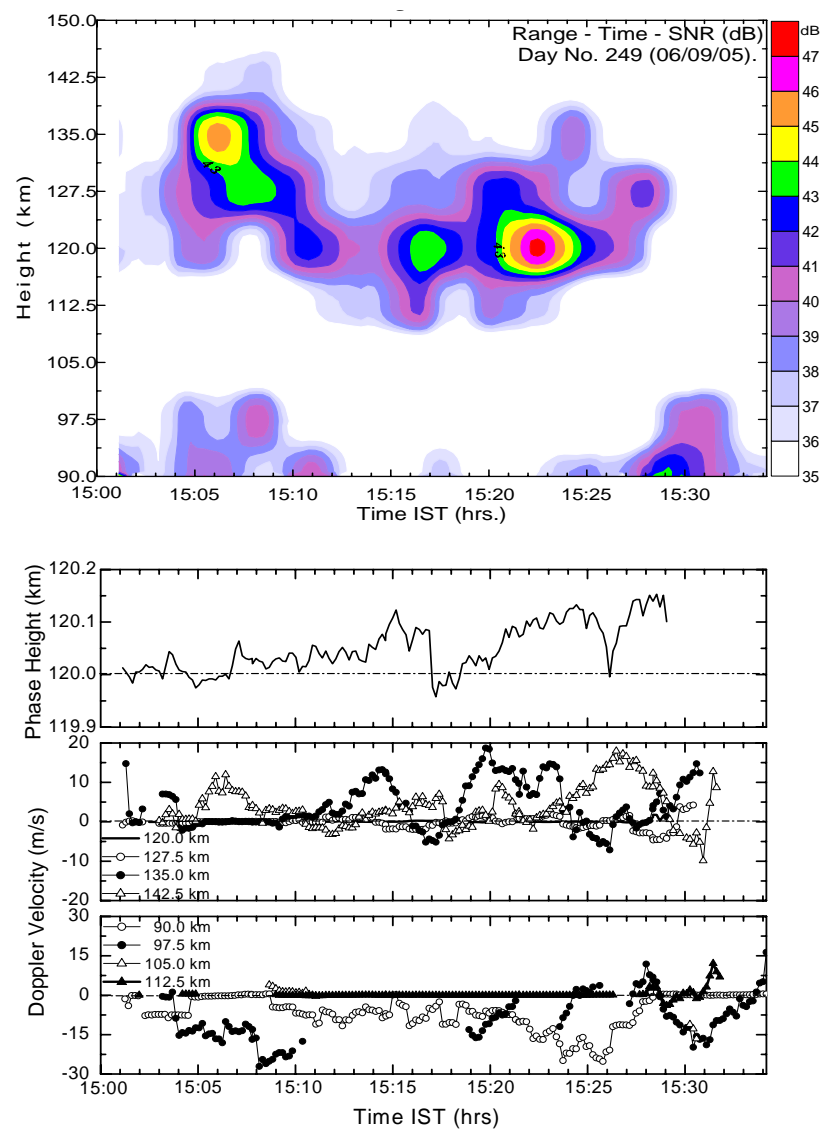

Fig. 4. Same as Fig. 2 except for the Day no. 249, 2005 (6 September 2005).

range bins to echo heights. The echoes with $\mathrm{S} / \mathrm{N}$ exceeding $35 \mathrm{db}$ only are plotted. However, the plots were drawn for the echoes with $10 \mathrm{~dB}$ SNR at the receiver output, since the process gain improves (nearly $25 \mathrm{~dB}$ ) with 512 point FFT. The RTS map plotted for 22 June 2005 (day no. 173), in Fig. 2, shows $E_{S}$ echo recorded during $1106 \mathrm{~h}$ to $1251 \mathrm{~h}$. The intense part of the echo is one transmitter pulse $(15 \mathrm{~km})$ wide centered around $112.5 \mathrm{~km}$ and the echo range some times is spread from $97 \mathrm{~km}$ to $142 \mathrm{~km}$. The bottom height of the $E_{S}$ is about $100 \mathrm{~km}$ and remained constant with time where as the top height showed small changes with time. The $\mathrm{S} / \mathrm{N}$ variations at each height are quasi-sinusoidal with $5 \mathrm{~min}$ to $12 \mathrm{~min}$ period. The bottom and top heights of the $E_{S}$ echoes do not show any variations with time. The occurrence of S/N maxima successively at lower altitudes at intervals of about $7 \mathrm{~km}$ with a delay of about $5 \mathrm{~min}$ is very significant.

In contrast during noon hours (Fig. 3 for 25 May 2005), large variation was observed in the bottom height through out the duration for which the echo is seen. The $\mathrm{S} / \mathrm{N}$ variations at each height are quasi-sinusoidal at intervals of $5 \mathrm{~min}$ to $10 \mathrm{~min}$. From the figure, we have observed echoes at $97.5 \mathrm{~km}$ altitude that most of the time are delayed by 3 to $6 \mathrm{~min}$ from those observed at higher altitude of $127.5 \mathrm{~km}$, though not
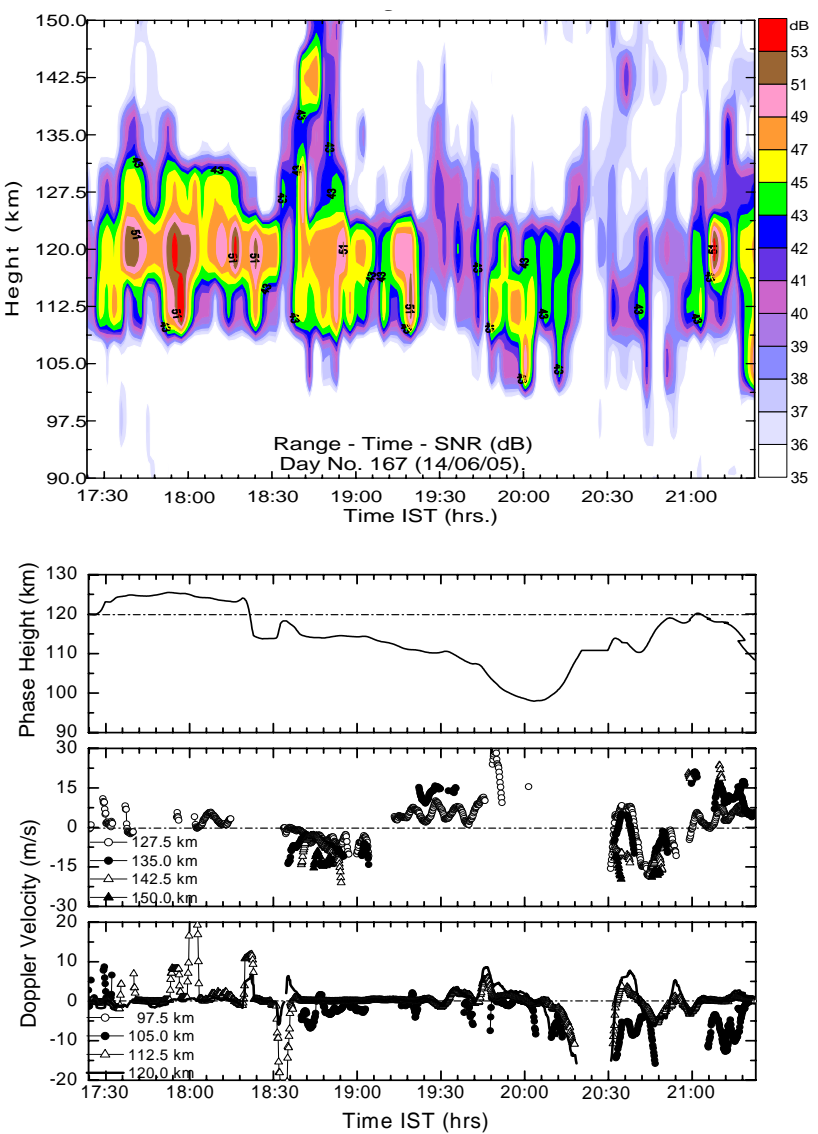

Fig. 5. Same as Fig. 2 except for the Day no. 167, 2005 (14 June 2005).

very consistently, which seem to reflect the characteristics of QP echoes in those cases.

During post noon hours (day no. 249 for 6 September 2005, shown in Fig. 4), the bottom height of $E_{S}$ echoes is below $90 \mathrm{~km}$. For this episode $E_{S}$ of two heights of S/N maxima, with no echo regions in between was observed. We could not probe altitudes below $90 \mathrm{~km}$ because of the limitation on the number of range bins to 16. The quasi-periods of the echo intensity variations are in the range of 4 to $8 \mathrm{~min}$ and the altitude of maximum intensity is at $120 \mathrm{~km}$ with S/N variations are similar to the variations during noon hours, but with a time delay of about $5 \mathrm{~min}$ between the $\mathrm{S} / \mathrm{N}$ maxima at lower heights.

During the post sunset hours (on day 167, i.e., 14 June 2005, Fig. 5) height occasionally crossed $150 \mathrm{~km}$ on the top side with periods in the range $10 \mathrm{~min}$ to $15 \mathrm{~min}$. The delayed occurrence of $\mathrm{S} / \mathrm{N}$ maxima at successive lower heights is not clear during the post sunset event as observed clearly for the other episodes. These variations imply partially range resolved echoes from discrete stratifications in the $E_{S}$ layer. For post mid night hours, (day no. 256: 13 September 2005 - Fig. 6) the $E_{S}$ echoes were observed from 90 to $127 \mathrm{~km}$ range with $7-10 \mathrm{~min}$ periodicity and with $\mathrm{S} / \mathrm{N}$ maximum at 
$112.5 \mathrm{~km}$. The delayed occurrence of $\mathrm{S} / \mathrm{N}$ maxima at successive lower heights was also seen not like post sunset event.

The overview of the RTS maps shows that the height of occurrence of $E_{S}$ is not constant with time. There are quasiperiodic variations of $\mathrm{S} / \mathrm{N}$ at each height and also the time of maximum $\mathrm{S} / \mathrm{N}$ at lower altitudes is delayed by about $5 \mathrm{~min}$ where as the $\mathrm{S} / \mathrm{N}$ maxima at each height are at intervals of 5 to $12 \mathrm{~min}$. The negative phase of the maximum intensity observed for successive lower altitudes shows the gravity wave influence on E-region heights. The contours of constant S/N are rather vertical but the maxima of $\mathrm{S} / \mathrm{N}$ at lower height only are delayed. The height of maximum intensity is higher for afternoon hours. The post sunset $E_{S}$ events appear to be of different characteristics compared to $E_{S}$ at other times of the day as the negative phase of the maximum intensity contour in the vertical plane is absent for post sunset hours.

\section{Phase height variations $E_{S}$ echo}

The phase height variations at the range bins where the echo intensity is highest for different times of the day corresponding to the RTS map shown in the top panel of each day are shown by dotted line in second panels of Figs. 2 to 6 . The phase height varies between 0.2 to $25 \mathrm{~km}$ with larger variation during post sunset hours compared to noon hours. For all days, these variations are less at the maximum intensity range than at the other ranges. The phase height variations with quasi periods of $10 \mathrm{~min}$ to $15 \mathrm{~min}$ are clearly observed for the noon time $E_{S}$ event shown in Fig. 3. During post noon hours when small phase height variations were observed, very small scale oscillations were overlapped on large scale variations. Continuous upward movement (i.e. + ve velocity) is observed for post midnight hours as shown in Fig. 6 for 13 September 2005.

\section{Doppler velocity variations of $E_{S}$ echoes at different times of the day}

The bottom two panels in Figs. 2 to 6 show the Doppler velocity maps of $E_{S}$ echoes corresponding to the RTS maps shown in top panels. Except for the range where the echo intensity is high, the velocities are plotted by line with different symbols. Velocity values for $\mathrm{S} / \mathrm{N}$ greater than $35 \mathrm{~dB}$ are only plotted resulting in discontinuous plots at each height when the $\mathrm{S} / \mathrm{N}$ was less than $35 \mathrm{~dB}$.

The lack of similarities in time variations of Doppler velocities even for adjacent heights is the most striking feature observed for almost all $E_{S}$ episodes under study. During pre-noon hours (Fig. 2), velocity is close to zero at heights $105 \mathrm{~km}$ through $112.5 \mathrm{~km}$ most of the time. At $97.5 \mathrm{~km}$ also the velocity was close to zero during $1100 \mathrm{~h}$ to $1155 \mathrm{~h}$, but during $1200 \mathrm{~h}$ to $1215 \mathrm{~h}$ the velocity decreased first and then increased to as much as $40 \mathrm{~m} / \mathrm{s}$. At $120 \mathrm{~km}$ to $150 \mathrm{~km}$ the velocity varied quasi-sinusiodally, some times with large mag-
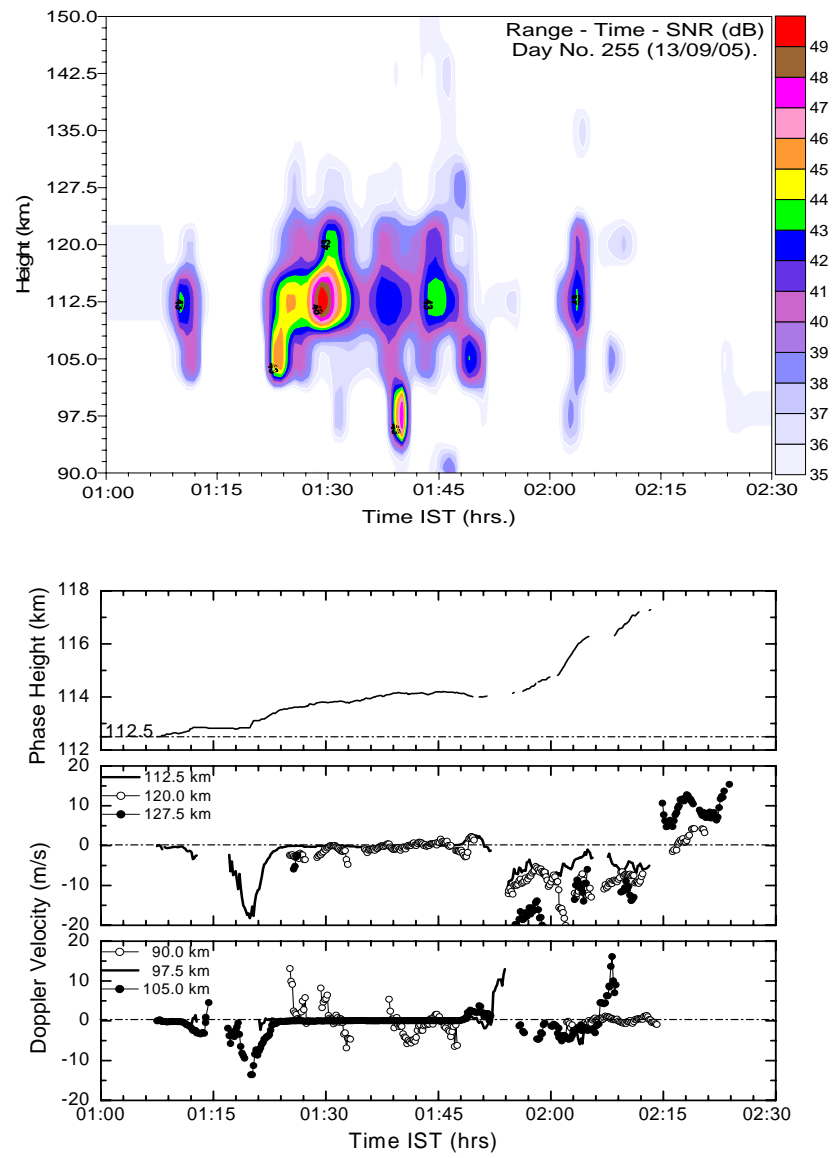

Fig. 6. Same as Fig. 2 except for the Day no. 256, 2005 (13 September 2005).

nitude, and the quasi-periods are even more than $20 \mathrm{~min}$, in contrast to 5-12 min periods observed in the RTS plots shown in the top panels. The velocity variations at higher range bins are with large magnitudes than at the lower range bins which show the diffusive character of the echoes from higher range bins. During post noon (Fig. 3), the velocity variations show quasi periodicity with periods ranging from 5 to $15 \mathrm{~min}$ ending with random variations. The velocity variations are similar for the upper ranges whereas random variations were observed for the lower ranges. During presunset hours (Fig. 4) the magnitude of velocity variations is larger for lower and higher range bins than at the range bins where echo intensity is highest. Also, there are high frequency variations of small magnitudes superposed on the large scale variations corresponding to very small scale variations observed in phase height. The quasi periods are ranging from 5 to $8 \mathrm{~min}$ for this event. The line of sight Doppler velocity variations bear no similarity with the echo intensity variations and in fact the velocity variations are small when the echo intensity variations are large and vice versa.

In general, the RTS and Doppler velocity variations of $E_{S}$ show quasi-periodic increases and decreases with periods 


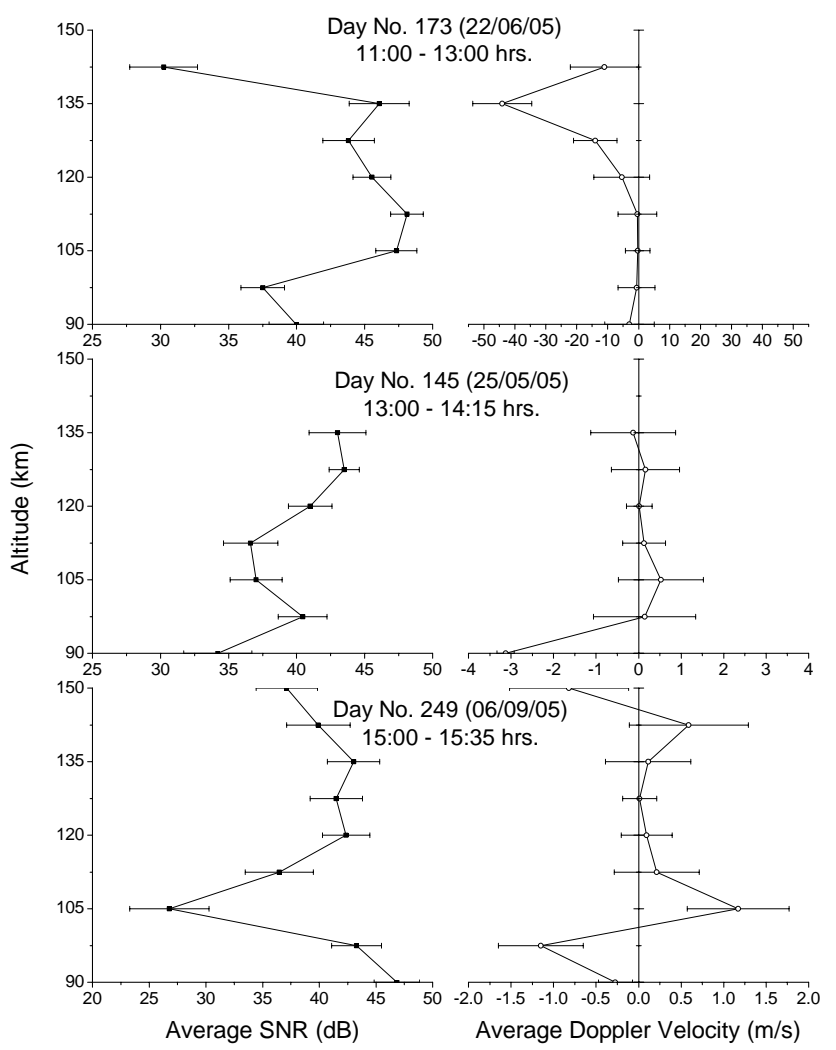

Fig. 7a. Altitude versus average SNR (left panels) and Doppler velocity (DV) (right panels) of individual $E_{S}$ occurrences on 173, 145 and 249.

varying from a few minutes to as large as 20 min implying the influence of medium scale TIDs at E-region heights over this low latitude. The lack of similarity in velocity variations for successive ranges (even though the transmitter pulse $(100 \mu \mathrm{s})$ is over-sampled at $50 \mu \mathrm{s}$ interval) indicates strong discrete reflecting layers within the altitude structure of the $E_{S}$ layer. In general, the velocity of the $E_{S}$ echoes is in between \pm 20 to $\pm 30 \mathrm{~m} / \mathrm{s}$ except for pre-noon hours when the velocities are as high as $70 \mathrm{~m} / \mathrm{s}$. The smaller velocities observed at the ranges where the echo intensity is highest can be interpreted as the accumulation ions because of the shear explained by the "Wind Shear Theory" (Whitehead, 1961).

\section{Profiles of range versus average echo intensity and av- erage line of sight velocity}

Figure 7a and $\mathrm{b}$ shows the profiles of Average SNR (AS) and Average Doppler Velocity (ADV) of $E_{S}$ layers observed during different times of the events reported in Figs. 2 to 6. The ADV for each range bin was computed only for echo intensity magnitudes more than 0.75 (arbitrary units). On all the days, except for the post midnight event, the average SNR shows two peaks indicating the discrete layer structure

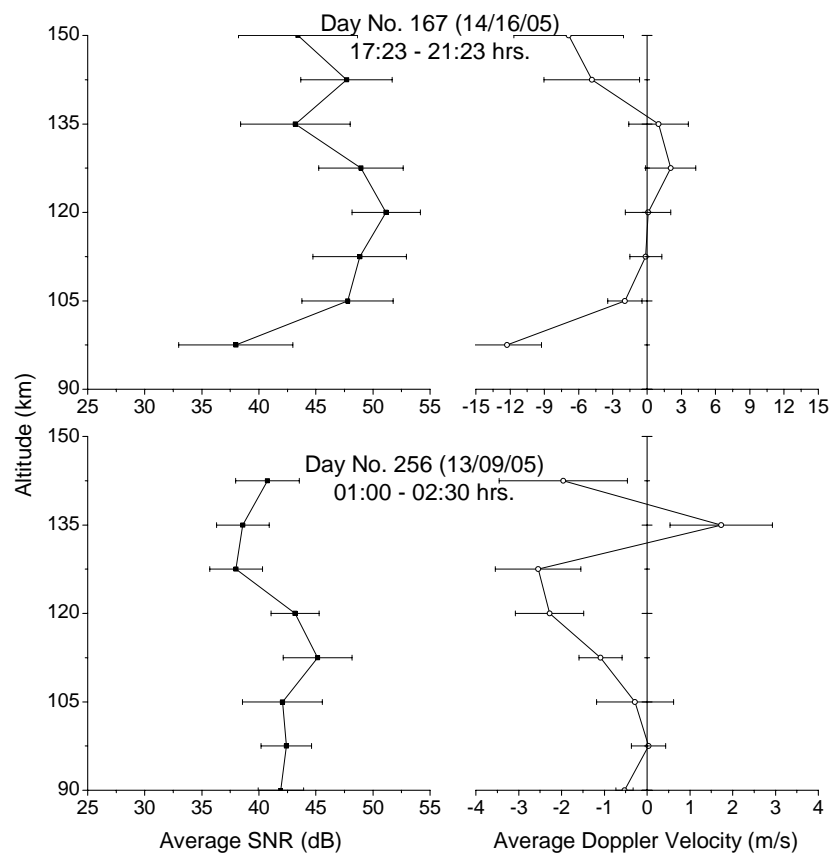

Fig. 7b. Same as Fig. 7a except for events occurred on 167 and 256.

within the $E_{S}$. The AS shows a prominent peak at $112.5 \mathrm{~km}$ during the pre noon hours. During pre sunset and post sunset hours the peak is at $120 \mathrm{~km}$ while it is at $112.5 \mathrm{~km}$ for the post midnight event. During post noon hours there are two peaks, the lower one at $97.5 \mathrm{~km}$ and the upper one at $127.5 \mathrm{~km}$. There is no similarity between the ADV velocity profiles and the AS profiles. The maximum ADV velocity varied with time and is below $5 \mathrm{~m} / \mathrm{s}$ except during pre noon and post sunset hours. For the post sunset $E_{S}$ occurrence, the maximum ADV was $15 \mathrm{~m} / \mathrm{s}$ upwards at $90 \mathrm{~km}$. It decreased to zero at $120 \mathrm{~km}$ and then increased to $12 \mathrm{~m} / \mathrm{s}$ upwards. The ADV is mostly upwards during other times with very small increases or decreases at a rate of less than $0.1 \mathrm{~m} / \mathrm{s}$. The average Doppler velocity attains high negative value at higher ranges implying upward movement of the $E_{S}$ echo. By and large, it can be observed that the range of maximum AS is not coinciding with the maximum ADV.

\section{Summary and discussion}

This paper reports the first observations on low latitude ionospheric E-region irregularities using a HF Doppler Radar with spectral capability. The major difference between those reported earlier and the present observations is that since this is a $5.5 \mathrm{MHz}$ Radar, the observations reflect the mean background dynamics when the irregularities are present and the salient observations are:

1. The density fluctuations as represented by the RangeTime-Signal to noise ratio (RTS) plots indicate quasi 
periodic variations with periods in the range $5-20 \mathrm{~min}$.

2. Lower velocities at the height of maximum density and relatively higher velocities at the top and bottom heights indicate the diffusive nature of the echoes.

3. The irregularity structure sometimes show the descending nature of the quasi periodic echoes indicating that the E-region irregularities as recorded by the HF Doppler Radar could be a mix of Sporadic E as well as the QP echoes.

4. The lack of similarity in the Doppler velocities even for adjacent heights indicates the background shear in the irregularity structure.

5. Echoes observed at E-region heights during post sunset and mid night hours show different characteristics with discrete stratifications and absence of delayed echoes at lower altitudes.

With spectrum capability, HF Doppler radar observations of $E_{S}$ echoes sampled in different range bins can provide an insight into the time variations of the layer structure and dynamics. The echo intensity variations with time obtained from HF Doppler radar spectra show 5 to 12 min quasi periodic increases and decreases, similar to the $150 \mathrm{~km}$ echoes reported extensively from VHF coherent back scatter radars (Yamamoto et al., 1991, 1992, 1994; Woodman et al., 1991; Tsunoda et al., 1994, 1995). It is well established that the $150 \mathrm{~km}$ echoes are produced by meter scale FAI for radar signals incident perpendicular to the magnetic field lines. It is, however, not clearly known whether the $E_{S}$ echoes in HF radars are also produced by coherent scatter from $27 \mathrm{~m}$ scale irregularities only or by reflection at the appropriate electron density level and diffraction effects and/or focusing of signal due to the phase variations across the reflected wave front due to the electron density irregularities close to the reflection level. It is important to note that the line of sight velocity of the $150 \mathrm{~km}$ echoes, also referred as QP echoes and valley region echoes, reported from VHF radars observations is between $-150 \mathrm{~m} / \mathrm{s}$ to $250 \mathrm{~m} / \mathrm{s}$ and further the velocity variations are random (Patra and Rao, 2006). The Doppler velocities observed in the present investigation at $5.5 \mathrm{MHz}$ are lower $(<30 \mathrm{~m} / \mathrm{s})$ than those reported from VHF radar observations. The $E_{S}$ echoing process, whether reflection and/or by coherent scattering from decameter scale FAI, can be resolved by measuring the directions of arrival of the echoes. Recently, Patra and Rao (2006) reported a necklace shaped local time variation, between $145 \mathrm{~km}$ to $155 \mathrm{~km}$, of the height of the $150 \mathrm{~km}$ echoes. We find that the altitude of maximum echo intensity varies from $105 \mathrm{~km}$ to $135 \mathrm{~km}$, but it is too premature to conclude a local time variation from the limited data presented in this study. It is interesting to note that during this study $E_{S}$ was not observed at $5.5 \mathrm{MHz}$ before 10:00 IST and the occurrence possibility is high in the noon time, thus suggesting the asymmetry of the instability mechanism causing $E_{S}$ with respect to the noon. It is also possible that the present observations using the HF Doppler Radar could be a mix of Sporadic E layer as well as the QP echoes.

The earliest HF radar observation of $E_{S}$ layers was explained by the wind shear theory (Dungey, 1956, 1959; Axford, 1961; Whitehead, 1961). Kherani et al. (2004) explained the presence of night time valley region echoes in VHF radars to be from irregularities produced by RayleighTaylor instability due to fringe (polarization) fields from the highly extended Spread F plumes. Cosgrove and Tsunoda (2001, 2002), described a direction-dependent instability, similar to Perkins instability (Perkins, 1973), of $E_{S}$ layers in the night time mid latitude ionosphere. He showed that the accumulation of $E_{S}$ ionization at the zonal wind shear node is unstable at night. During night time the F layer and $E_{S}$ layers in mid latitudes are a coupled system and that the kilometer scale Hall electric fields in $E_{S}$ map efficiently between $E_{S}$ and $\mathrm{F}$ layers. Cosgrove and Tsunoda (2002) described a fragmentation process of $E_{S}$ layer involving a closed current system between the two dynamos on either side of the wind shear node producing electric fields larger than the $U \times B$ by a factor equal to or even larger than the ratio of the field line integrated Hall and Pedersen conductivities. $E_{S}$ layer modulation by gravity waves or $\mathrm{KH}$ instability billows were proposed to produce the large electric fields. It is, however known, that gravity waves exist almost always in the E-region and the fact that $E_{S}$ layers are not observed very frequently is probably due to the directional dependence of the instability during the night time (Casagrove and Tsunoda, $2002 b$ ). Our observation that the $E_{S}$ layer echo intensity in different range bins is modulated by 5 to 20 min quasi periods both during day time and night time, and the QP echoes at $150 \mathrm{~km}$ are also observed during day time in low latitudes (Patra and Rao, 2006) is to be investigated in terms of the gravity wave modulation of the irregularities during different times of the day.

Maruyama et al. (2006) found a close relationship between the appearance of QP echoes in the RTI plot and the level of in-homogeneity in Sporadic E plasma, signified by the difference between $f_{b} E_{S}$ and $f_{o} E_{S}$. During QP echo events, $f_{o} E_{S}$ increased while $f_{b} E_{S}$ decreased so that the difference between these two enhanced indicating the development of strong spatial structuring in electron density within the sporadic $\mathrm{E}$ layer. To investigate this feature, we have shown in Fig. 8 (top panel) the time variation of $f_{b} E_{S}$ and $f_{o} E_{S}$ for noon time on day 173 (22 June 2005) when Es was observed at $5.5 \mathrm{MHz}$ on the HF Doppler Radar. As reported by Maruyama et al. (2006), we also have observed an increase in the difference between the two supporting the above arguments. But on the other hand, we have observed cases of QP echoes on HF Doppler Radar with no increase in the difference between the $f_{b} E_{S}$ and $f_{o} E_{S}$ (bottom panel of Fig. 8 for day 249, 6 September 2005) and hence the correlation is not perfect. Patra et al. (2005) also found rather a 

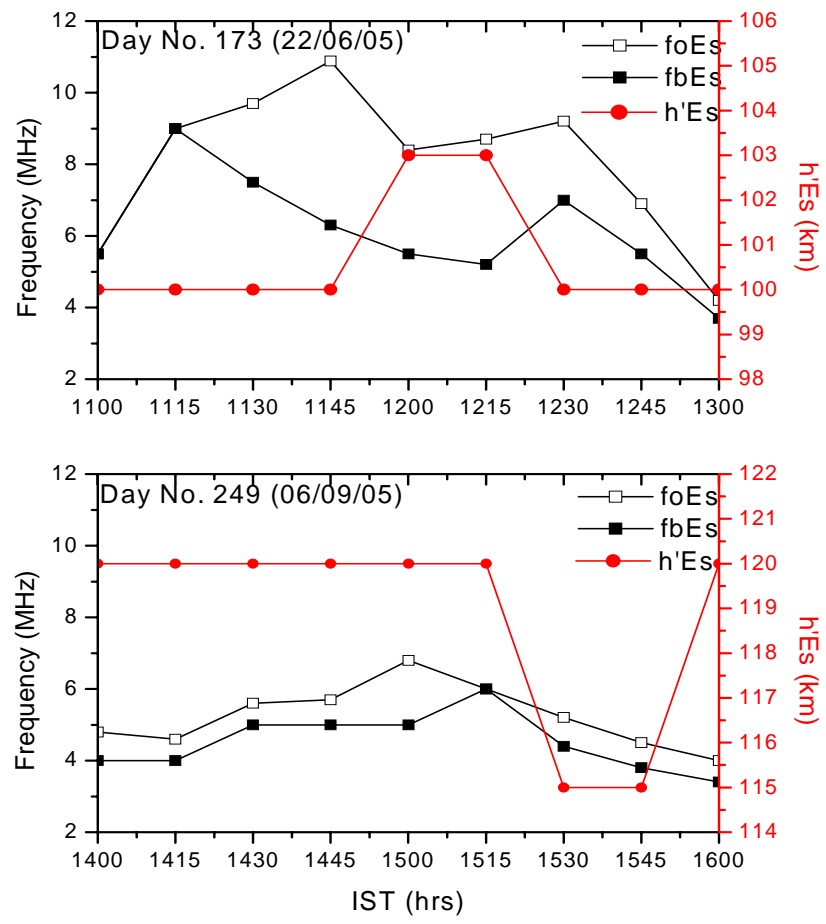

Fig. 8. Time variations of $f_{o} E_{S}, f_{b} E_{S}$ and $h^{\prime} E_{S}$ for pre noon (top panel) and post noon (bottom panel) hours.

poor correlation between coherent back scatter obtained with Gadanki MST Radar and $f_{T} E_{S}-f_{b} E_{S}$ from SHAR during night. The development of spatial in-homogeneity as evidenced by the difference in $f_{o} E_{S}$ and $f_{b} E_{S}$ is necessary for the onset of QP echoes which confirmed the results of Ogawa et al. (2002) at mid latitudes, but did not agree well with the recent findings of Patra et al. (2005) and the present observations at low latitudes. Patra et al. (2005) reported that the most intense echo is below the virtual height of $E_{S}$ layer during daytime while it is either above or below during night. The strength of the FAI is better correlated with the top penetration frequency $f_{t} E_{S}$ and $f_{b} E_{S}$ during night than during day. The relationship between Radar and Es parameters derived from Ionograms is poorer than that of mid latitudes which is quite consistent with the expectations based on gradient drift instability.

QP structures are often embedded in descending echoing region which are reminiscent of tidal ion layers (Chau and Woodman, 1999; Mathews, 1998) and thus indicate the role of tidal and gravity waves in the observed features. Yamamato et al. (1991) have shown that QP striations in which SNR peaks at two different altitudes as was observed in some of the cases shown in Fig. 7a and b. Further, QP echoes at higher altitudes with undulations at lower altitudes can be understood in terms of altitude variation of the efficiency of gravity waves in modifying the underlying plasma (Choudary and Mahajan, 1999). Occurrence of QP echoes at higher altitudes during night time hours may be associated with descending intermediate ion layers which descend down to upper E-region altitudes (Mathews, 1998) as reported by Rao et al. (2008). Kherani et al. (2004) reported that the night time valley region echoes could also be because of the downward extension of the Spread F irregularities from F-region altitudes and hence the observed night time echoes show different structures.

Acknowledgements. This work is supported by CSIR and ISRO under CAWSES-India Programme.

Topical Editor M. Pinnock thanks K. Oyama and another anonymous referee for their help in evaluating this paper.

\section{References}

Axford, W. L.: Note on a mechanism for the vertical transport of ionization in the ionosphere, Can. J. Phys., 39, 1393-1396, 1961.

Balsley, B. B.: Evidence of stratified echoing region at $150 \mathrm{~km}$ in the vicinity of magnetic equator during daylight hours, J. Geophys. Res., 69, 1925-1930, 1964.

Blank, E., Mercandalli, B., and Houngninou, E.: Kilometric irregularities in the $\mathrm{E}$ and $\mathrm{F}$ regions of the day time equatorial ionosphere observed by high resolution HF radar, Geophys. Res. Lett., 23, 645-648, 1996.

Cosgrove, R. B. and Tsunoda, R. T.: Polarization electric fields sustained by closed-current dynamo structures in midlatitude sporadic E, Geophys. Res. Lett., 28, 1455-1458, 2001.

Cosgrove, R. B. and Tsunoda, R. T.: Wind-shear-driven, closedcurrent dynamos in midlatitude sporadic E, Geophys. Res. Lett., 29(2), 1020, doi:10.1029/2001GL013697, 2002.

Chau, J. L.: Unexpected spectral characteristics of the VHF radar signals from 150-km region over Jicamarca, Geophys. Res. Lett., 31, L23803, doi:10.1029/2004GL021620, 2004.

Chau, J. L. and Woodman, R. F.: Low-latitude quasi periodic echoes observed with the Piura VHF radar in the E region, Geophys. Res. Lett., 26, 2167-2170, 1999.

Chau, J. L. and Woodman, R. F.: Daytime vertical and zonal velocities from 150-km region over Jicamarca, Geophys. Res. Lett., 31, L23803, doi:10.1029/2004GL020800, 2004.

Choudhary, R. K. and Mahajan, K. K.: Tropical E region field aligned irregularities: Simultaneous observations of continuous and quasiperiodic echoes, J. Geophys. Res., 104, 2613-2619, 1999.

Choudhary, R. K., St. Maurice, J. P., and Mahajan, K. K.: Observations of coherent echoes with narrow spectra near $150 \mathrm{~km}$ altitude during daytime away from the dip equator, Geophys. Res. Lett., 31, L19801, doi:10.1029/2004GL020299, 2004.

de Paula, E. R. and Hysell, D. L.: The Sao Luis $30 \mathrm{MHz}$ coherent scatter ionospheric radar: System description and initial results, Radio Sci., RS1014, doi:10.1029/2003RS002914, 2004.

Dungey, J. W.: The influence of the geomagnetic field as turbulence in the ionosphere, J. Atmos. Terr. Phys., 8, 39-42, 1956.

Dungey, J. W.: Effect of a neutral turbulence in an ionized gas, J. Geophys. Res., 64, 2188-2191, 1959.

Ecklund, W. L., Carter, D. A., and Balsley, B. B.: Gradient drift irregularities in mid latitude sporadic E, J. Geophys. Res., 86, 858-862, 1981.

Fejer, B. G. and Kelley, M. C.: Ionospheric irregularities, Rev. Geophys., 18, 401-454, 1980. 
Haldoupis, C.: A review on radio studies of auroral E-region ionospheric irregularities, Ann. Geophys., 7, 239-258, 1989.

Hysell, D. L., Larsen, M. F., and Woodman, R. F.: JULIA radar studies of the electric fields in the equatorial lectrojet, Geophys. Res. Lett., 24, 1687-1690, 1997.

Kato, S.: Cross-field instability for the formation of sporadic E, Radio Sci., 7, 417-423, 1972.

Keys, J. G. and Andrews, M. K.: Gravity wave and sporadic-E echo signatures on VHF backscatter radar system, Planet. Space Sci., 32, 1455-1462, 1984.

Kherani, E. A., Paula, E. R., and Bertoni, F. C. P.: Effects of the fringe of Rayleigh-Taylor instability in the equatorial E and valley regions, J. Geophys. Res., 109, A12310, doi:10.1029/2003JA010364, 2004.

Kudeki, E. and Fawcett, C. D.: High resolutio observations of $150 \mathrm{~km}$ echoes at Jicamarca, Geophys. Res. Lett., 20, 19871990, 1993.

Kudeki, E., Fawcett, C. D., Ecklund, W. L., Johnston, P. E., and Franke, S. J.: Equatorial 150-km irregularities observed at Pohnpei, Geophys. Res. Lett., 25, 4079-4082, 1998.

Maruyama, T., Saito, S., Yamamoto, M., and Fukao, S.: Simultaneous observation of sporadic $\mathrm{E}$ with a rapid-run ionosonde and VHF coherent backscatter radar, Ann. Geophys., 24, 153-162, 2006, http://www.ann-geophys.net/24/153/2006/.

Mathews, J. D.: Sporadic E: Current views and recent progress, J. Atmos. Solar Terr. Phys., 60, 413-435, 1998.

Ogawa, T., Takahashi, O., Otsuka, Y., Nozaki, K., Yamamoto, M., and Kita, K.: Simultaneously middle and upper atmosphere radar and ionospheric sounder observations of midlatitude E-region irregularities and Sporadic E-layer, J. Geophys. Res., 107(A10), 1275, doi:10.1029/2001JA900176, 2002.

Patra, A. K., Sripathi, S., Rao, P. B., and Subbarao, K. S. V.: Simultaneous VHF radar backscatter and ionosonde observations of low-latitude E region, Ann. Geophys., 23, 773-779, 2005, http://www.ann-geophys.net/23/773/2005/.

Patra, A. K. and Venkateswara Rao, N.: Radar observations of daytime $150-\mathrm{km}$ echoes from outside the equatorial electrojet belt over Gadanki, Geophys. Res. Lett., 33, L03104, doi:10.1029/2005GL024564, 2006.

Perkins, F.: Spread F and ionospheric currents, J. Geophys. Res., 78, 218-226, 1973.

Rao, N. V., Patra, A. K., and Rao, S. V. B.: Some new aspects of low-latitude E-region QP echoes revealed by Gadanki radar: are they due to Kelvin-Helmoltz insteability or gravity waves?, J. Geophys. Res., 113, A03309, doi:10.1029/2007JA012574, 2008.

Riggin, D., Swartz, W. E., Providakes, J., and Farley, D. T.: Radar studies of long wave-length waves associated with midlatitude sporadic E layers, J. Geophys. Res., 91, 8011-8024, 1986.
Royrvik, O.: Drift and aspect sensitivity of scattering irregularities in the upper equatorial E-region, J. Geophys. Res., 87, 8338$8342,1982$.

Royrvik, O. and Miller, K. L.: Nonthermal scattering of radio waves near $150 \mathrm{~km}$ above Jicamarca, Peru, J. Geophys, Res., 86, 180 188, 1981.

Simon, A.: Instability of a partially ionized plasma in crossed electric and magnetic fields, Phys. Fluids, 6, 382-388, 1963.

Tanaka, T. and Venkateswaran, S. V.: Charecteristics of field aligned E-region irregularities over Iioka $\left(36^{\circ} \mathrm{N}\right)$, Japan. I, J. Atmos. Terr. Phys., 44, 381-393, 1982a.

Tanaka, T. and Venkateswaran, S. V.: Charecteristics of field aligned E-region irregularities over Iioka $\left(36^{\circ} \mathrm{N}\right)$, Japan. II, J. Atmos. Terr. Phys., 44, 395-406, 1982b.

Tsunoda, R. T., Fukao, S., and Yamamoto, M.: On the origin of quasi-periodic radar back scatter from midlatitude sporadic E, Radio Sci., 29, 349-365, 1994.

Tsunoda, R. T., Livingstone, R. C., Buonocore, J. J., and Mckinley, A. V.: The frequency agile radar: A multi-functional approach to remote sensing of the ionosphere, Radio Sci., 30, 1623-1643, 1995.

Tsunoda, R. T. and Euklund, W. L.: On the nature of 150-km radar echoes over the magnetic dip equator, Geophys. Res. Lett., 27, 657-660, 2000.

Tsunoda, R. T. and Casgrove, R. B.: Azimuth-dependent $E_{S}$ layer instability: A missing link found, J. Geophys. Res., 109, A12303, doi:10.1029/2004JA010597, 2004.

Whitehead, J. D.: The information of the sporadic E layer in the temperate zones, J. Atmos. Terr. Phys., 20, 49-58, 1961.

Woodman, R. F.: Spectral moment estimation in MST radars, Radio Sci., 20, 1185-1195, 1985.

Woodman, R. F., Yamamoto, M., and Fukao, S.: Gravity wave modulation of gradient drift instabilities in midlatitude sporadic-E irregularities, Geophys. Res. Lett., 18, 1197-1200, 1991.

Yamamoto, M., Fukao, S., Woodman, R. F., Ogawa, T., Tsuda, T., and Kato, S.: Midlatitude E region field aligned irregularities observed with the MU radar, J. Geophys. Res., 96, 15943-15949, 1991.

Yamamoto, M., Fukao, S., Ogawa, T., Tsuda, T., and Kato, S.: A morphological study on midlatitude $\mathrm{E}$ region field-aligned irregularities observed with MU radar, J. Atmos. Terr. Phys., 54, 769777, 1992.

Yamamoto, M., Komoda, N., Fukao, S., Tsunoda, R. T., Ogawa T., and Tsuda, T.: Spatial structure of the E region filed aligned irregularities revealed by the MU radar, Radio Sci., 29, 337-347, 1994. 